\title{
Using Policy Labs as a process to bring evidence closer to public policymaking: a guide to one approach
}

Saba Hinrichs-Krapels (i) ${ }^{1 凶}$, Jocelyn Bailey², Harriet Boulding ${ }^{1}$, Bobby Duffy ${ }^{1}$, Rachel Hesketh ${ }^{1}$, Emma Kinloch ${ }^{1}$ Alexandra Pollitt', Sarah Rawlings ${ }^{1}$, Armida van Rij ${ }^{1}$, Benedict Wilkinson ${ }^{1}$, Ross Pow ${ }^{3}$ \& Jonathan Grant ${ }^{1}$

\begin{abstract}
While robust evidence is one ingredient in the policymaking process, it is by no means the only one. Engaging with policymakers and the policymaking process requires collaborative working models, navigating through the experiences, values and perspectives of policymakers and other stakeholders, as well as communicating evidence in an accessible manner. As a response to these requirements, over recent years there has been proliferation of activities that engage producers of evidence (specifically, academics), policymakers, practitioners, and the public in policy formulation, implementation and evaluation. In this article, we describe one engagement approach for facilitating research evidence uptake into policy and practice-an activity called a 'Policy Lab' - as conducted by the team at The Policy Institute at King's College London on numerous policy challenges over the past four years. Drawing on our experience in running 15 Policy Labs between January 2015 and September 2019, we (a) provide a guide to how we have run Policy Labs, while sharing our learning on what has worked best in conducting them and (b) demonstrate how these labs can contribute to bringing evidence closer to policymaking, by comparing their characteristics to enablers for doing so identified in the literature. While this approach to Policy Labs is not the only one of its kind, we suggest that these types of Labs manifest characteristics identified in previous studies for influencing the policymaking process; namely: providing a forum for open, honest conversations around a policy topic; creating new networks, collaborations and partnerships between academics and policymakers; synthesising available evidence on a policy topic in a robust and accessible format; and providing timely access to evidence relevant to a policy issue. We recognise the limitations of measuring and evaluating how these Labs change policy in the long-term and recommend viewing the Policy Lab as part of a process for engaging evidence and policymaking and not an isolated activity. This process serves to build a coalition through participation of diverse communities (thereby establishing 'trust'), work on the language and presentation of evidence (thereby enabling effective 'translation' of evidence) and engage policymakers early to respond when policy windows emerge (thereby taking into account 'timing' for creating policy action).
\end{abstract}

\footnotetext{
${ }^{1}$ King's College London, The Policy Institute, London, UK. ${ }^{2}$ University of the Arts London, Social Design Institute, London, UK. ${ }^{3}$ Power of Numbers, London, UK. ${ }_{\text {email: saba.hinrichs@kcl.ac.uk }}$
} 


\section{Introduction}

he challenges of bringing research evidence into public policymaking have been discussed extensively in previous literature, much of which has been included in this article series 'The politics of evidence-based policymaking: Maximising the use of evidence in policy ${ }^{1}$. What is evident from these studies is a common understanding that policymaking requires much more than the presentation of evidence, no matter how robust and convincing it is. Over recent years there has been proliferation of activities that engage producers of evidence (specifically, academics), policymakers, practitioners and the public in the policymaking process. In this article, we focus on one engagement approach for facilitating research evidence uptake into policy and practice: Policy Labs. The term 'Policy Lab' can refer to different things: they can range from established teams (or organisations or institutes) set up specifically for innovative activities for public policymaking, to physical spaces set up for the purpose of conducting workshops or activities for policymaking. These teams, spaces and/or activities are referred to by terms that include 'public innovation lab', 'public sector innovation lab', 'government innovation lab', 'organisational innovation lab', 'policy innovation lab', 'innovation lab', 'public policy lab', 'social innovation lab', 'systems change lab', 'living lab', 'design lab', and simply 'policy lab'. We have mapped these different types of Policy Labs, networks and institutes elsewhere and do not report on those here. (Bailey et al., 2020)

\section{Aim and approach}

In this article we make clear that we are referring to a Policy Lab as an activity and/or process, not an established institute/team nor a physical space for innovative activities. Our aim is to (a) provide a guide to how we have run Policy Labs (a total of 15 between January 2015 and September 2019), while sharing our learning on what has worked best and (b) demonstrate how these labs can contribute to bringing evidence closer to policymaking, by comparing their characteristics to enablers for doing so identified in the literature. For the purposes of this article, we are writing as practitioners who run these formats of Policy Labs (along with other similar engagement activities) and base our reflections on key studies previously published in this area.

Literature: enablers to bringing evidence closer to policymaking. While barriers to the uptake of expertise and analysis in policymaking had already been identified in the 1970s (Weiss, 1979; Caplan, 1979), a number of recent studies have identified ways of overcoming these barriers. In this article we make no attempt to systematically review the literature on this topic, as this has been done comprehensively by other scholars. Our aim is to highlight key enablers to bringing evidence to policymaking that have already been identified in these studies. We focus particularly on two related systematic reviews due to their comprehensive coverage on the subject of bringing evidence closer to policymaking. The first systematic review by Oliver et al. (2014) reviewed academic literature to identify barriers and enablers affecting the use of evidence in all areas of public policy (an update to a previous review by Innvaer et al. (2002)); and the second systematic review from Oliver and Cairney (2019) identified 'how-to' advice for academics to get their evidence into policy, across both academic and non-academic literature.

We summarise these enablers in Table 1, where we have grouped them into three guiding principles that have served us in understanding our contributions to improving the evidence-topolicy divide: Trust, Translation and Timing.

The first set of enablers centre around the principle of 'trust'; effectively acknowledging the need for better interactions between producers of evidence (in this case, academics) and their consumers (policymakers). Both reviews strongly emphasise the importance of establishing collaborations and good relationships between academics and policymakers. As remarked in one of our blogs, policymaking is messy, iterative and little understood, just like sausage- and law-making (Grant and Wilkinson, 2014). Values, experience, culture, public perception and emotions-all of these are at play when any individual makes decisions, including policymakers seeking the use of evidence (Davies, 2015). A recent European Commission Joint Research Centre report highlighted the need to defend the role of evidence in policy, while recognising the complex values and beliefs which permeate our framing and decision-making (Mair et al., 2019). As a response to these challenges, some studies have pointed to the use of more collaborative working models, whereby policymakers are engaged in the research early on, rather than merely viewed as consumers of the evidence (Nutley et al., 2002). Universities and institutes are also establishing policy institutes, networks and activities that bring evidence and policymaking closer together (Sasse and Haddon, 2018, 2019; Walker et al., 2019). These academic institutions are engaging in what has been described as 'policy brokerage', a university-driven knowledge exchange activity that 'operates at the intersection between academia, policy and societal impact" ${ }^{\prime 2}$ Part of the approaches these networks and institutes employ are to co-design, which have been described by Oliver and Cairney (2019) as 'widely held to be morally, ethically, and practically one of the best ways to... getting evidence into policy' especially in some opinion, practitioner-based accounts, while having more collaborations generally between academics and policymakers was identified as one of the main enablers for bringing evidence into policymaking in academic literature (Oliver et al., 2014). 'Trust' can also refer to retaining integrity in the production of evidence; ensuring academics produce 'high-quality research' (Oliver and Cairney, 2019; Boyd, 2013; Whitty, 2015; Docquier, 2017) and are 'explicit about methodologies, limitations and weaknesses' (Whitty, 2015).

By 'translation' we refer to the importance of communication between academics and policymakers (Feldman et al., 2001); the ability to translate academic research into accessible and relevant messages, or to make research 'relevant and readable' (Oliver and Cairney, 2019). The policymaking process involves people who have to take decisions under often time-constrained, pressured circumstances-and making sense of evidence can be challenging under any circumstances. Mayne et al. (2018) rightly point out that no policymaker can consider all evidence relevant to decisions, as there is more information available than any individual or governing organisation could process. Knowing how to choose the appropriate type of evidence for making policy and practitioner decisions is difficult, which is where systematic reviews are useful, and why guidance exists for understanding what counts as good evidence as well as how to decide how to use it (Nutley et al., 2013). In a review of strategies to increase the uptake of evidence in health policy, Moore et al. (2009) found that the context of the research is also important: presenting the research in such a way that demonstrates its applicability to the specific circumstance at hand, also referred to as finding 'relevance' for the evidence in Cartwright and Hardy's (2012) guide for evidence-based policy. A helpful reflective editorial piece from a previous UK Chief Scientific Adviser on what makes a paper useful for (health) policy stresses the importance of writing papers that are rigorous in their methods but written in clear, simple form with a clear connection to a policy problem (Whitty, 2015). According to Davies (2015), a consistent finding from the research utilisation literature is that research and evaluation reports are often seen as inaccessible to 
Table 1 Key enablers to bring evidence closer to policymaking from literature.

\section{Collaboration (Oliver et al., 2014)}

Relationship with policymakers (Oliver et al., 2014)

Building relationships with policymakers (Oliver and Cairney, 2019)

Relationship with researchers/info staff (Oliver et al., 2014)

(Academics who) understand policy process (Oliver and Cairney, 2019)

(Academics who) engage routinely, flexibly and humbly (Oliver and Cairney, 2019)

Availability and access to research/improved dissemination (Oliver et al., 2014)

Clarity/relevance/reliability of research findings (Oliver et al., 2014)

High-quality research (Oliver and Cairney, 2019)

Research relevant and readable (Oliver and Cairney, 2019)

Trust
Trust
Trust
Trust
Timing; Trust
Timing; Translation
Translation; Trust

Translation; Trust decision-makers. The study by Lavis et al. (2005) on improving the usefulness of systematic reviews for health care managers and policymakers recommends a 'graded-entry' presentation of evidence (e.g., one page of take-home messages, a three-page executive summary and a 25-page report).

Finally, while making sense of available evidence and relationship building is important, 'time' is an important factor. Policymaking takes place in an unpredictable environment with many policymakers and influencers interacting at many levels and types of government (Mayne et al., 2018). The classic 'policy window' described by Kingdon (1984) is a way of highlighting the importance of policy, politics and problems colliding at the right time for policymaking to take action. Oliver and Cairney (2019) point out the need to be 'accessible' to policymakers-while they mainly refer to the need to engage 'routinely and humbly', this regular accessibility is what can then enable the research to reach the policymaker at the right time. The continuous challenge for researchers, as described by Davies (2015), is to 'identify the best available evidence in the time frame in which decisions have to be taken, whilst also developing a more robust evidence base for future policy-making in the medium to longer term'.

The development of our version of Policy Labs were a direct response to these challenges and enablers. Conceptualised not as a standalone event, but as a process of engagement, the labs involve building a coalition through participation of diverse communities (thereby establishing 'trust'), working on the language and presentation of evidence (thereby enabling effective 'translation') and engaging policymakers early to respond when policy windows emerge (thereby taking into account 'timing' for creating policy action). In the next section we describe our approach and learning from this process.

Reporting on our experience: 8-step guide to running Policy Labs. We ran a total of 15 Policy Labs between January 2015 and September 2019 (see Box 1 for selected examples), which involve the following eight steps. Our intention in this brief description is not to give a full outline of what occurs within a lab, as this can vary for each project, but to provide a general description of the types of steps involved.

1. Set aside time for planning. Considerable work and preparation go into Policy Labs (roughly between 20 and 40 days of staff time, spread out across a team), as each lab demands a bespoke design that is appropriate to the topic, context and invited participants' views. It is easy to underestimate how much thought is required to identify the right question or topic to be addressed at the lab. This resonates with the experience of initiatives adopting 'design thinking' for public services; emphasising that to frame the (policy) problem correctly from the start is 'a pre-condition for the effective unfolding of the phases of policy formulation, development, adoption and implementation' (Allio, 2014).
Typically, this stage has involved anything from 5 to 10 hours of consultations with the research and Policy Lab preparation team. Crucially, the preparation stage involves having a good understanding of the key areas of evidence, gaps in knowledge and potentially sources of contention from anticipated discussions.

2. Establish the need and purpose of the Policy Lab. Our Policy Lab model tackles issues at any stage of the policymaking process: questions can address policy problem identification, policy formulation, implementation or evaluation of policies, or any of the steps in between these stages (see Fig. 1 for examples). The issue to be tackled at the Policy Lab is dependent on the stage of development of the particular public policy area and whether there is existing evidence to support this stage. For 'earlier stage' policy formulation labs (i.e., at agenda setting, Cairney, 2016, p. 17, or policy formulation stage), the lab may demonstrate that current evidence is not yet available for establishing a policy agenda, in which case the result may be to establish a research and future policy agenda. The Policy Lab in this case serves to explore a nascent, potentially controversial idea that has not yet been researched thoroughly and lacks a robust evidence base, but builds on similar evidence perhaps in another policy or sector scenario. An example of this is the Policy Lab on 'Positioning the UK within the global research landscape' (Box 1), which explored scenarios for how the UK university sector's international relationships could change on departure from the European Union. If some evidence is readily available on what approaches could work in particular settings, the lab may serve to formulate options for policy design and plan for future policy evaluation. If evidence is available and policy has already been formulated but is struggling to be implemented, the lab can serve to identify barriers and facilitators to uptake, such as the lab on diabetes (Box 1). In this diabetes Policy Lab example, advice on including bariatric surgery as a treatment option for Type 2 diabetes already existed in the National Institute for Health and Care Excellence (NICE) guidelines; however, challenges persisted in relation to the uptake of bariatric surgery among patient populations whom it could benefit. The Policy Lab helped unpack the reasons behind these challenges and examine potential routes for improved adoption and implementation of the NICE guidelines. Finally, if the lab is exploring a policy that is already being trialled and implemented, but not formally evaluated, the lab may serve to take a step back and explore evaluation options.

The need for a lab is sometimes driven by a fellow researcher identifying a requirement to explore the implications for their potential research project/programme in changing public policy and/or practice (i.e., a 'push' for policymaking). In other instances, policymakers identify an issue that would benefit from an in-depth interrogation of the evidence from the perspectives of a range of stakeholders, as well as the resulting fresh ideas that this might generate (i.e., a 'pull' from policymakers). The nature 
Box 1. Examples of Policy Labs conducted by the Policy Institute, King's College London. Unless otherwise stated, the outcomes are based on our own reflections

\section{Policy Lab: The role of metabolic/bariatric surgery as a treatment option for type 2 diabetes (September 2015)}

Topic: The lab aimed to identify practical and conceptual barriers to the use, where appropriate, of bariatric surgery for the treatment of type 2 diabetes. It was motivated by a desire to better understand how to engage policymakers in a discussion about the effective use of metabolic surgical resources in conjunction with other interventions in good diabetes practice.

Participants: Twenty-six including academics, clinicians, policymakers, industry leaders and patient representatives

Length: $4 \mathrm{~h}$

Report: Journal article

Outcomes: The lab helped to crystallise existing thinking on the role of bariatric surgery in the treatment of type 2 diabetes, especially for patients of higher BMI. Our synthesis of the lab's findings was presented to attendees of the World Congress on Interventional Therapies for Type 2 Diabetes, drawing special attention to articulating the barriers that needed to be overcome to include the option of bariatric surgery within the range of treatments for type 2 diabetes. Subsequently, although we cannot claim our contribution to this process, the NICE diabetes guidelines were updated in 2018 to include a link to the obesity guidelines to recommend bariatric surgery as an option for type 2 diabetes patients of higher BMIs (NICE guidelines, 2015).

Policy Lab: Towards a Cavity-free future (July 2017)

Topic: Driven by the Alliance for a Cavity-free Future (ACFF), this lab addressed the question of how to increase resource allocation for caries prevention and control. Despite the evidence and desire for change among many health professionals, caries prevention is not prioritised globally and there are financial, regulatory and cultural shifts needed.

Participants: Twenty-five including academics, Chief Dental Officers, Public Health groups, the British Dental Association and representatives from across all faces of dentistry.

Length: 1.5 days (an afternoon session and informal dinner, followed by close to a full day)

Report(s): Summary report (Pitts et al., 2017) and 1-page infographic used for immediate dissemination

Outcomes: The summary report provided focussed evidence on why caries is a problem with associated solutions, while the infographic served an advocacy document at a worldwide congress held shortly after the lab. Attendees committed to taking the Policy Lab messages to practitioners, patients and industry globally. It was resolved by the group that a useful next step would be to find a way to demonstrate the monetary value of a cavity- free future, and to look into ways to promote models for prevention focused payment systems for dentists, better equipping the dental and related health workforces to deliver effective caries prevention and management. This led to a follow-up Policy Lab a year later focussing on paying for health in dentistry, which had more tangible outcomes, such as: a sub-group formed with the Wales Chief Dental Officer to work with the Welsh Government to draw up plans for implementation of a new local payment system pilot for dentistry; the production of a 'CariesCare Practice Guide' with the British Dental Journal to advance the concepts recommended by the Policy Lab; and the payment models implemented as a trial for a new payment system in France.

\section{Policy Lab: Positioning the UK within the global research landscape (March 2017)}

Topic: This Policy Lab sought to explore the UK's place in the global research landscape in a range of possible futures, varying in terms of access to resources/infrastructure and access to skills/talent.

Participants: c20 policymakers, professional bodies, universities, research funders, researchers

Length: 1 full day, 10:00-16:00

Report: Policy brief (with briefing pack as an online annex), Op-ed

Outcomes: The policy brief was used for advocacy purposes by professional bodies that represented the UK university sector. It also influenced internal policy within King's College London and built relationships among participants for further work and advocacy activities.

Policy Lab: The future of the Mental Health Act Policy Lab (November 2017)

Topic: The lab aimed to support the independent review of the Mental Health Act by considering the approaches the review could take to progressing six key 'areas of tension'.

Participants: c22 policymakers, researchers, service user representatives, legal practitioners and clinicians

Length: 1 full day

Report(s): Report (Owen et al., 2018) and Policy brief (Stephenson et al., 2019); small launch event for participants to discuss the findings with other key invited guests; follow-on evidence session in the House of Lords to further discuss particular proposals around 'advance choice' documents (one of the key areas highlighted by participants during the lab).

Outcomes: The independent review team found the outputs of the lab useful and cited the policy brief in the published review. It also influenced ongoing work to implement 'advance choice' documents in mental health care.

of what they wish to achieve can lie anywhere along an exploration-formulation-implementation spectrum.

3. Select and invite participants. Participant selection depends on the types of questions that will be addressed and the stage of policymaking that the lab will address (Fig. 1). For example, a lab that exists to explore options for future policy implementation may require high-level government ministers, as well as implementers who can identify barriers and facilitators to change in practice. In many cases it is important to include those groups whom the policy or practice is designed to benefit, i.e., the endusers and/or beneficiaries, who may have the most direct experience of the effects of current practice and insights into failures and successes.
Key to the success of many labs has been to sympathise, understand and engage with the participants that are presentrecognising their mix of perspectives, expertise and the values they bring to the table. This may mean inviting people who are assumed to have opposing views on the topic to be discussed (for example, those who might be expected to be particularly resistant to a change in policy or practice), and using the Policy Lab as a forum to consider different points of view, which may shed light on barriers to implement changes. At times, the people sitting in the room are those that create or present barriers to change, and may be persuaded to shift their perspectives as a result of the discussions. Ideological beliefs may harm progress during the lab (but is sometimes inevitable) and it is helpful when participants are able to recognise the value of evidence and engage with ideas 


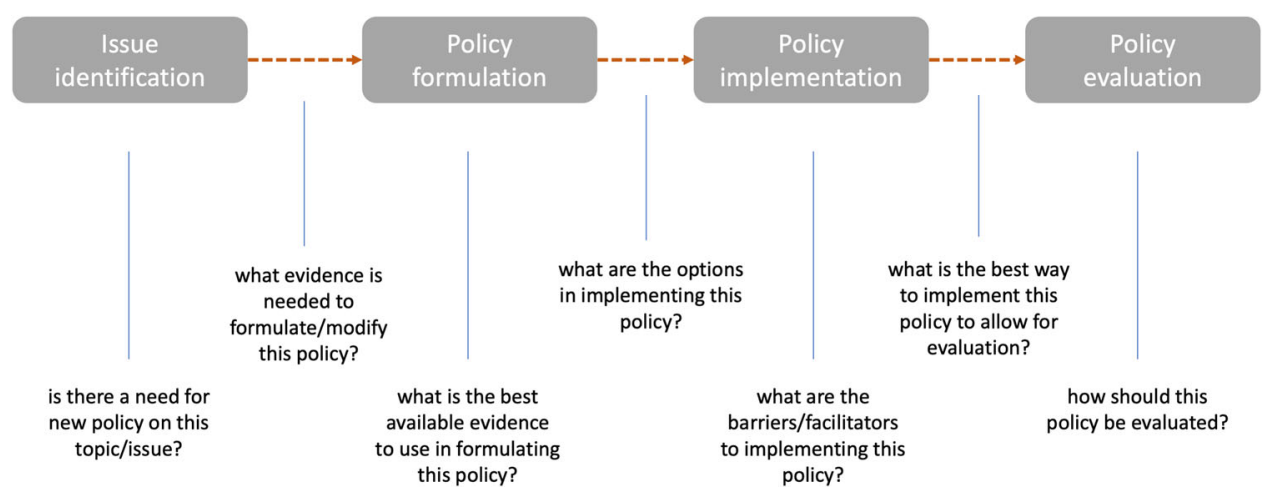

Fig. 1 Sample Policy Lab questions. These are examples of the types of questions that can be addressed in a Policy Lab, corresponding to different actvities within policymaking, such as identification of policy issues, formulating policies, implementation, and the evaluation of policies.

other than their own views. Ultimately, the Policy Lab brings people together to engage with the evidence and listen to each other, thereby building a coalition of understanding, which may encourage taking action following the lab.

4. Synthesise and communicate the evidence. Whilst perspectives, values and experiences are at play when making decisions, our vision is to bring evidence (if available) closer to policymaking. For that to happen effectively, we cannot rely on traditional academic presentations of evidence or long, inaccessible papers. We send all participants a 'briefing pack' in advance that serves two purposes: (i) to make it easier for participants to work through all available evidence and data on the topic in advance, and (ii) to ensure that everyone has been exposed to the same information for discussions to be based on a common knowledge base. The pack includes, for example, the latest evidence on the topic, examples of current practice in the field, examples of good practice internationally and preliminary findings from research that is currently taking place. With the exception of one lab (the diabetes Policy Lab, Box 1), there was no existing systematic collection of evidence that comprehensively covered the full scope of the topic to be discussed, and so careful thinking and discernment comes into selecting the type of evidence to ensure there is a balance of perspectives. Only studies of strong quality are included; if systematic reviews or other forms of peerreviewed syntheses already exist on a topic, these findings are prioritised and summarised succinctly. The art of the briefing pack is in identifying the point at which the existing evidence becomes ambiguous, insufficient or where there is substantial disagreement. It aims to set out in an accessible way the widely accepted evidence base, ensuring that participants arrive for the lab with an agreed understanding of the issue, while leaving disagreements and evidence gaps to be tackled during the lab itself. A fine balance is needed between over-simplification and too much technical detail.

5. Plan agenda and facilitation. The length of a Policy Lab can vary. In the Dentistry Policy Lab example (Box 1), we invited guests from other countries and provided accommodation for one night, to continue the meeting the next day. This also allowed for further informal discussions to take place in the evenings, as well as some time for thinking to evolve before the second session. Our lab on diabetes (Box 1) was attached to an existing conference and was slotted in as a 4-h event in an evening, with presentations given to a wider conference audience the next morning. Other labs have typically lasted a full (6-h) day, long enough that nothing else can be scheduled that day and short enough to allow for travel requirements and concentration levels on the day. Essentially the timing will depend on the anticipated dynamics of the group and how to keep everyone focussed; too short, and there may not be time for ample discussion; too long, and participants can lose concentration and discussion can become circular.

In order to navigate through differences in views and keep the group dynamics, it is important to choose the right facilitator, especially one familiar with participatory decision-making (Kaner, 2014). They need not be an expert in the topic discussed but should have the skills and expertise in engaging people, sympathising with their views and moving the discussions forward in a productive manner. We often invited an external facilitator and ensured they were heavily involved in the design of the lab and the identification of the topics for discussion. For some Policy Labs, especially those in other countries, we are mindful of the need to be culturally sensitive when choosing a facilitator to ensure participants are at ease and engaged, taking into account language, gender, age and profession.

6. Conduct the Policy Lab. The lab itself can take on different forms, but generally starts with a welcome and presentations based on the information that was sent out in the briefing back. It is important to establish that this is a safe space to share divergent ideas and encourage active, transparent and creative participation. Although the briefing pack should attempt to be clear, unambiguous, and avoid jargon, this is also a good time to allow participants to provide some feedback on what was missing or anything with which they disagreed. This allows the meeting to start with everyone having had time to express their views and agree on some common ground before starting the discussions.

The rest of the lab generally involves a combination of breakout and plenary sessions, exploring key questions for the topic, prioritising ideas and reaching consensus, if appropriate. For example, the questions might include: 'Is the evidence compelling or is more research needed to scale up this intervention?' 'What are the barriers to further implementation?' 'How can these barriers be overcome?' 'What is the best set of 'ingredients' to deliver the goals under different possible futures?'. We have used a combination of techniques in these break-out sessions, including incorporating competitive games for a promising idea, or the use of basic props such as arts materials (as inspired by the Cabinet Office Policy Lab, Kimbell, 2015). Some of our labs have drawn on a 'diamond' approach (Kaner, 2014) to the session: questions and discussions are initially encouraged to broaden thinking (welcoming new ideas on a topic, ignoring any constraints and, encouraging open creativity), and the second part of the session involves narrowing down and focussing on more practical, realistic and implementable steps forward. 

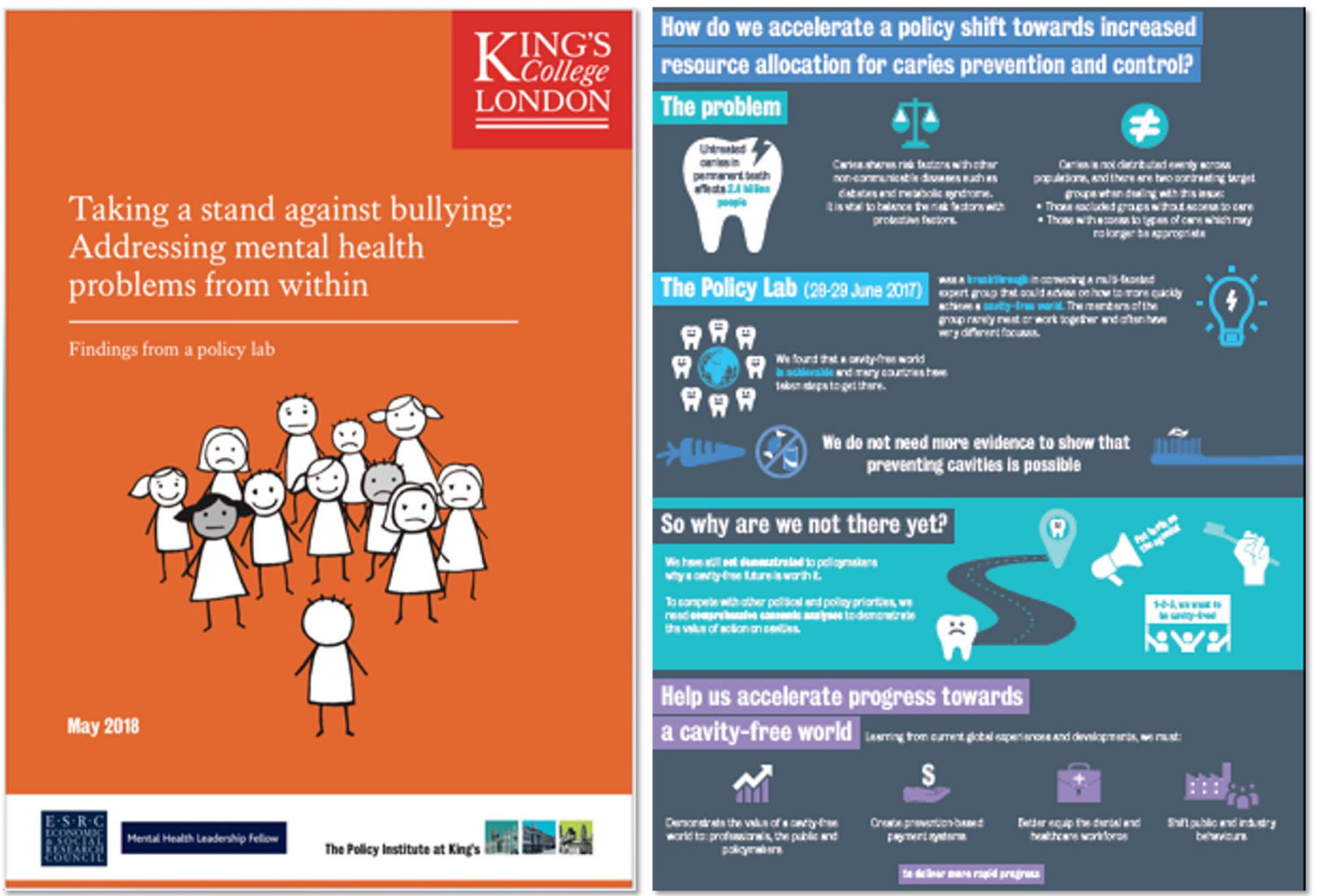

Fig. 2 Examples of Policy Lab reports. The figure on the left is the front cover of the final report for a policy lab on addressing bullying; the figure on the right is a summary infographic from the policy lab on re-allocating resources for tackling caries prevention.

Alternatively, the lab can follow something similar to the Situation-Complication-Question process devised by Minto (2009): First the status quo or accepted 'situation' is presented, followed by a known problem or 'complication' to that situation, which seeks to build a consensus with those in the room, and to then find a suitable 'question' that can address that complication, which will drive the Policy Lab discussions.

7. Report the results. These labs tend to generate a large volume of ideas in a short space of time, so it is important to have a systematic way to capture and distil the key messages that will best take forward the proposed policy/practice change. Participants have often commented on their surprise by both the breadth and the depth of the insights obtained. Results from these discussions are summarised in a format that is accessible to a non-academic audience, such as a policy briefing or pamphlet (Fig. 2), but may also result in a journal article (Rubin et al., 2016). The format of the report needs to support the engagement and advocacy requirements following the lab: the dental labs (Box 1) were a good example of this, as they combined an immediate one-page infographic (Fig. 2) that enables fast follow-up with key stakeholders with an accompanying structured report that was produced later and was timed to target decision-makers and key influencers at a particular point in time (i.e., a major conference) -an approach similar to the 'graded-entry' alluded to earlier (Lavis et al., 2005).

8. Create and support the new coalition. While we have so far discussed the of the lab in terms of the level of engagement and facilitation on the day, it is the long-term outcomes that are particularly important in the context of bringing evidence closer to, and improving the effectiveness of, policymaking. Here, realism is key: policymaking is beyond our control and beyond the control of a single lab. Actions after the Policy Lab will depend on the participants themselves and the outcomes and/or agreements made during the meeting. For example, briefing documents or pamphlets summarising key recommendations from the lab are printed and distributed, used for advocacy purposes and followup meetings are planned to continue and consolidate plans for policy action (e.g., formulation or implementation plans). Here, we found that finding one person or team to champion an idea or agenda can be helpful. Another way to ensure ongoing work is to ask for pledges from the participants for the coming 6-12 months and plan to reconvene after this time to discuss progress. Alternatively, a commitment is made for a change or action by the participants (e.g., to change regulations or policy documentation on an issue). Resource constraints have sometimes limited our own team's ability to engage beyond the briefing document sent after the day, so an agreed commitment from collaborators to continue the work can help devise an informed and targeted advocacy, communications and engagement strategy for followup. Having engaged in co-creation (Bason, 2010) of the lab's outcomes through their engagement on the day, it is important to empower the participants to feel ownership of the outcomes and therefore become its advocates.

Discussion: the role of Policy Labs as a process to bring evidence to policymaking. The Policy Labs described in this article were designed as a response to a need to bring evidence and policymaking closer together, while acknowledging that academic evidence is only one ingredient in the policymaking process. Our 
underlying assumption with these activities is that policymaking can be improved through access to the latest research, thinking and evidence (playing the role of 'policy brokerage' alluded to earlier), but also through innovative approaches, tools, methods, practices and interactive spaces to bring different stakeholders together. Some of the approaches we adopt directly respond to the enablers identified in the literature for bringing evidence closer to policymaking. In this section we refer to steps 1-8 outlined in the previous section and summarise three ways in which these Policy Lab activities manifest the characteristics of these enablers: (i) creating new networks; collaborations and partnerships between academics and policymakers; (ii) synthesising available evidence on a policy topic in a robust and accessible format; and (iii) providing timely access to evidence relevant to a policy issue.

(i) Networks, collaborations and partnerships between academics and policymakers. Summarised under our theme of 'trust', both academic and non-academic literature points to the importance of building trusted relationships between academics and policymakers, as well as codesigning and collaborating on policy problems (Oliver et al., 2014; Oliver and Cairney, 2019). The lab is designed to deliberately bring together people with opposing views and different perspectives on a topic, in order to openly discuss solutions and thereby connecting them in a common goal (step 3). By co-creating ideas, they jointly become advocates for the lab outcomes and new, trusted relationships are built (step 8). It has also been recommended for academics to get to know the policymaking process and policymakers (Tyler, 2017). In many cases, these labs have given academics an opportunity to realise that the evidence presented, while 'correct' in terms of academic integrity, may not always be appropriate due to political, resource and/or budget constraints (addressed in the discussions on barriers and facilitators in step 6). The discussions give both the producers of evidence and those with policy decision-making powers an opportunity to consider which constraints are binding and which are more malleable, to co-design solutions that can work in practice. They also help connect researchers' work into the wider policy landscape, hence magnifying their awareness of how their work fits into potentially other sectors and public policy areas. Moreover, the spirit with which the labs are conducted are of transparency, openness, willingness to learn and critically examining the evidence, with the unifying goal of solving the public policy issue. This can be moderated with the appropriate mix of activities and facilitation (step 5), and ensuring participants understand this is a 'safe space' to share divergent ideas (step 6).

(ii) Robust and accessible synthesis of available evidence on a policy topic. A second set of enablers in previous literature pointed to the need to 'translate' academic research or to make research 'relevant and readable' (Oliver and Cairney, 2019) and increase the clarity, relevance and reliability of research (Oliver et al., 2014). For these Policy Labs, great effort is placed upon creating a well-synthesised briefing pack (step 4) that outlines strengths and weaknesses in available evidence on the policy topic, and a message-driven final report (step 7) designed support the engagement and advocacy requirements following the lab. Studies have shown that there is little consensus on what counts as good evidence among policymakers (see for example, Oliver and de Vocht, 2015 and Nutley et al., 2013). As described by Oliver and Cairney (2019), its 'credibility, legitimacy and usefulness' is gathered through its connections to individuals' networks and topical issues (Boaz et al., 2015; Oliver and Faul, 2018). This reinforces the importance of creating a forum and a process for engagement with evidence by both policymakers and academics, to unpack its strengths and weaknesses and advance the gaps in evidence that are relevant for policymaking, which the Policy Lab approach is designed to do. Academics leave with a better understanding of how and whether further evidence is needed on a topic, while policymakers and practitioners leave with a better understanding of whether and how the available evidence can be used to make the next policy and practice decisions.

(iii) Timely access to evidence relevant to a policy issue. Given the differences in timing for academic writing and policy decisions, 'timing' has been identified as an inevitable barrier in bringing evidence closer to policymaking (Oliver et al., 2014). The Policy Lab was deliberately designed to be flexible-to contribute to imminent policy decisions, as well as developing ideas for future policymaking. From the content of the briefing pack (step 4), to selection of participants (step 3) and focus of discussions on the day (step 6), each Policy Lab is strictly focussed on the policy issue to be discussed and the concerns of those invited. This gives policymakers an opportunity to engage with evidence early and allows them to respond when the window for taking action may occur (if it is not already within the bounds of the lab itself).

Our approach to Policy Labs may not be the only one of its kind, but we offer this guide as an illustration of how they can be a way of bringing evidence closer to policymaking, especially if they are conducted with the above three characteristics. To do this effectively, however, requires a great deal of flexibility so that the Policy Lab can be used in any stage of the policymaking cycle (from agenda setting to implementation and evaluation).

We are aware of challenges in measuring Policy Labs' longerterm outcomes beyond the immediate benefits of responding to barriers of bringing evidence closer to policymakers. It can be challenging to secure the resources needed (e.g., in terms of staff time) to follow-up on specific outcomes that may have been influenced in a policymaking impact pathway. Policymaking also remains messy and complicated, and corroborating how one particular lab or interactive workshop has nudged a decision in a particular direction is difficult in the absence of documented evidence of such an impact. To our knowledge, two of the 15 Policy Labs conducted have influenced a policy decision (Box 1), which we can track through citations of our Policy Lab reports. We also know of conversations and further meetings that have taken place after the Policy Labs, which were a result of bringing people together in a lab setting-highlighting the importance of being proactive in creating follow-up activities. Beyond these engagements we recognise the limitations of these Policy Labs in being able to change policy themselves. The likelihood of impact can be magnified if the lab is part of a wider process of policy development that is already happening (i.e., getting 'timing' right), which was the case in the contribution to the review of the Mental Health Act (Box 1).

With that in mind, we feel it is important to view Policy Labs not as standalone events but as part of a long-term process of engagement between academics and policymakers, which may later contribute to more effective policymaking as a future outcome. A historical and conceptual account of the policy innovation lab by Williamson (2015) describes labs as 'combining elements of the work of think tanks, designers, political and social scientific research', which resonates with the approach we have described. Specifically, we have alluded to elements of design 
thinking throughout the description of these labs, which advocates the bringing together of diverse stakeholders in cocreation (Bason, 2010) and co-design. As in other similar design approaches, the participants in our labs play a 'responsible, active and constructive role in shaping decisions' and are not passive receivers of public policy decisions (Allio, 2014).

\section{Conclusions}

Engaging with policymakers and the policymaking process requires collaborative working models, navigating through the experiences, values and perspectives of policymakers and other stakeholders, and communicating evidence in an accessible manner. These Policy Labs we have held were designed with a recognition that policymaking involves much more than just evidence, and provides a space in which the values, emotions, experiences and perceptions of different stakeholders are expressed and exploited, alongside evidence. The labs seek to draw out a wide range of perspectives and views to ensure that options and ideas are challenged and deliberated. The process includes preparatory work such as mapping of policies, plans, resources and regulations; monitoring policy contents, contexts, actors and processes; and identifying barriers and enablers of change. This process culminates in one or more collaborative workshops bringing together diverse stakeholders (the wider community of policy and practice) around a particular challenge to engage with the evidence, listen to each other, understand barriers and constraints, and co-develop new ideas and approaches to improve outcomes.

While this approach to Policy Labs is not the only one of its kind, we suggest that these types of labs manifest characteristics identified in previous studies for influencing the policymaking process; including creating new networks, collaborations and partnerships between academics and policymakers; synthesising available evidence on a policy topic in a robust and accessible format; and providing timely access to evidence relevant to a policy issue.

We recognise the limitations of measuring and evaluating how these labs change policy in the long-term and recommend to view the Policy Lab not as an isolated activity but as part of a process for engaging producers of evidence (academics) and their consumers (policymakers), with a view to bringing evidence closer to policymaking in the long-term. Specifically, the Policy Lab process is designed to build a coalition through participation of diverse communities (thereby establishing 'trust'), work on the language and presentation of evidence (thereby enabling effective 'translation' of evidence) and engage policymakers early to respond when policy windows emerge (thereby taking into account 'timing' for creating policy action).

Beyond tracking whether or not these Policy Labs have influenced change in individual policy decisions, we are also conscious of our broader aim to contribute to a culture shift in the way policymaking occurs and feel we are making a contribution in this space. We welcome comments and feedback from others reading this article who have tried similar approaches to share learning and contribute to the pool of approaches to improved policymaking.

\section{Data availability}

All datasets analysed are included in the paper.

Received: 12 September 2019; Accepted: 25 March 2020;

Published online: 01 June 2020

\section{Notes}

1 Palgrave Communications. The Politics of Evidence-based Policymaking: Maximising the Use of Evidence in Policy. Editor: Professor Paul Cairney.
2 Taken from the description of a mapping project of policy brokerage functions undertaken in 2018 by Sarah Chaytor and Dr. Olivia Stevenson at UCL, and Professor James Wilsdon, Dr. Jasper Montana and Natalie Day at the University of Sheffield

\section{References}

Allio L (2014) Design thinking for public service excellence. UNDP Global Centre for Public Service Excellence. Available at: https://www.undp.org/content/ undp/en/home/librarypage/capacity-building/global-centre-for-publicservice-excellence/DesignThinking.html. Accessed 30 Apr 2020

Bailey J, Hinrichs-Krapels S, Pollitt A, Duffy B (2019) Policy and Innovation Lab Landscape Review. Technical Internal Document. The Policy Institute, King's College London

Bason C (2010) Leading public sector innovation: co-creating for a better society. Policy press

Boaz A, Locock L, Ward V (2015) Whose evidence is it anyway? Evidence and policy. https://doi.org/10.1332/174426515X14313738355534

Boyd I (2013) Research: a standard for policy-relevant science. Nature 501 (7466):159-160. https://doi.org/10.1038/501159a

Cairney P (2016) The politics of evidence-based policy making. Springer

Caplan N (1979) The two-communities theory and knowledge utilization. Am Behav Scientist 22(3):459-470

Cartwright N, Hardie J (2012) Evidence-based policy: A practical guide to doing it better. Oxford University Press

Davies P (2015) Getting evidence into policy and practice. J Dev Effectiveness 7 (4):393-401

Docquier D (2017) Communicating your research to policy makers and journalists-Author Services: Support Taylor and Francis Authors. Available at: https://authorservices.taylorandfrancis.com/communicating-science-topolicymakers-and-journalists. Accessed 30 Apr 2020

Feldman PH, Nadash P, Gursen M (2001) Improving communication between researchers and policy makers in long-term care: or, researchers are from Mars; policy makers are from Venus. Gerontologist 41(3):312-321

Grant J, Wilkinson B (2014) Sausages, evidence and the messiness of policymaking (Blog). In Policy Wonkers. Available at: https://blogs.kcl.ac.uk/ policywonkers/tag/evidence-based-policy. Accessed 30 Apr 2020

Innvaer S, Vist G, Trommald M, Oxman A (2002) Health policymakers' perceptions of their use of evidence: a systematic review. J Health Serv Res Policy $7: 239-244$

Kaner S (2014) Facilitator's guide to participatory decision-making. John Wiley \& Sons Kimbell L (2015) Applying design approaches to policy making: discovering Policy Lab. University of Brighton

Kingdon J (1984) Agendas, Alternatives and Public Policies New York: Harper Collins Lavis J, Davies H, Oxman A, Denis J-L, Golden-Biddle K, Ferlie E (2005) Towards systematic reviews that inform health care management and policy-making. J Health Serv Res Policy 10(suppl 1):35-48. https://doi.org/10.1258/ 1355819054308549

Mair D, Smillie L, La Placa G, Schwendinger F, Raykovska M, Pasztor Z, van Bavel $\mathrm{R}$ (2019) Understanding our political nature: How to put knowledge and reason at the heart of political decision-making. EUR 29783 EN. Publications Office of the European Union, Luxembourg

Mayne R, Green D, Guijt I, Walsh M, English R, Cairney P (2018) Using evidence to influence policy: Oxfam's experience. Palgrave Commun 4(1):122

Minto B (2009) The pyramid principle: logic in writing and thinking. Pearson Education

Moore G, Todd A, Redman S (2009) Strategies to increase the use of evidence from research in population health policy and programs: a rapid review. NSW Health. Available at: https://www.health.nsw.gov.au/research/Documents/10strategies-to-increase-research-use.pdf. Accessed 30 Apr 2020

NICE guidelines (2015) Type 2 diabetes in adults: management NICE guideline [NG28], National Institute for Health and Care Excellence. Published date: December 2015 Last updated: Aug 2019

Nutley S, Davies H, Walter I (2002) Evidence based policy and practice: Cross sector lessons from the UK. ESRC UK Centre for evidence based policy and practice: working paper, 9. Available at: https://www.kcl.ac.uk/sspp/ departments/politicaleconomy/research/cep/pubs/papers/assets/wp9b.pdf. Accessed 30 Apr 2020

Nutley SM, Powell AE, Davies HTO (2013) What counts as good evidence? Alliance for useful evidence. Available at: https://www.alliance4usefulevidence. org/publication/what-counts-as-good-evidence-february-2013. Accessed 30 Apr 2020

Oliver K, Faul MV (2018) Networks and network analysis in evidence, policy and practice. Evid Policy 14(3):369-379. https://doi.org/10.1332/ $174426418 X 15314037224597$

Oliver K, Innvar S, Lorenc T, Woodman J, Thomas J (2014) A systematic review of barriers to and facilitators of the use of evidence by policymakers. BMC health Serv Res 14(1):2

Oliver K, Cairney P (2019) The dos and don'ts of influencing policy: a systematic review of advice to academics. Palgrave Communications 5(1) 
Oliver KA, de Vocht F (2015) Defining “evidence" in public health: a survey of policymakers' uses and preferences. Eur J Public Health. ckv082. https://doi. org/10.1093/eurpub/ckv082

Owen G, Pollitt AR, Wilkinson BJ, Jones LEB, Pow R (2018) The future of the mental health act. The Policy Institute, King's College London. Available at: https://www.kcl.ac.uk/policy-institute/assets/future-of-the-mental-health-act. pdf. Accessed 30 Apr 2020

Pitts NB, Grant J, Hinrichs-Krapels S, Mazevet ME (2017) Towards a Cavity-Free Future: How Do We Accelerate a Policy Shift Towards Increased Resource Allocation for Caries Prevention and Control? The Policy Institute, King's College London. Available at: https://www.kcl.ac.uk/policy-institute/researchanalysis/towards-a-cavity-free-future. Accessed 30 Apr 2020

Rubin JK, Hinrichs-Krapels S, Hesketh R, Martin A, Herman WH, Rubino F (2016) Identifying barriers to appropriate use of metabolic/bariatric surgery for type 2 diabetes treatment: Policy Lab results. Diabetes Care 39(6):954-963

Sasse T, Haddon C (2018) How government can work with academia. Institute for Government. Available at: https:/www.instituteforgovernment.org.uk/sites/ default/files/publications/IfG_government_academia_June_2018_vb.pdf. Accessed 30 Apr 2020

Sasse T, Haddon C (2019) How academia can work with government. Institute for Government. Available at: https://www.instituteforgovernment.org.uk/sites/ default/files/publications/IfG_Academic_and_gov_2019_WEB_FINAL.pdf. Accessed 30 Apr 2020

Stephenson L, Gergel T, Owen G, Ruck Keene A, Pollitt A, Wilkinson B (2019) The future of advance decision making in the mental health act. policy brief. The Policy Institute, King's College London. Available at: https://www.kcl.ac.uk/ policy-institute/assets/adm-mental-health-act.pdf. Accessed 30 Apr 2020

Tyler C (2017) Wanted: academics wise to the needs of government. Nature 7. https://doi.org/10.1038/d41586-017-07744-1

Walker L, Pike L, Chambers C, Lawrence N, Wood M, Durrant H (2019) Understanding and navigating the landscape of evidence-based policy: recommendations for improving academic-policy engagement. University of Bath. Available at: https://www.bath.ac.uk/publications/understanding-and-navigating-thelandscape-of-evidence-based-policy/attachments/understanding-and-navigatingthe-landscape-of-evidence-based-policy.pdf. Accessed 30 Apr 2020

Weiss CH (1979) The many meanings of research utilization. Public Adm Rev 39 (5):426-431

Whitty CJM (2015) What makes an academic paper useful for health policy? BMC Med 13(1):301. https://doi.org/10.1186/s12916-015-0544-8

Williamson B (2015) Governing methods: policy innovation labs, design and data science in the digital governance of education. J Educ Adm Hist 47 (3):251-271

\section{Acknowledgements}

We are grateful to everyone who has contributed to the design and delivery of our Policy Labs, and to Niall Sreenan for proofreading an earlier version of this manuscript.

\section{Author contributions}

SHK designed and conceptualised the article and mainly wrote the manuscript. JB, RH, AvR, AP, BW, HB, EK, SR, JG contributed content, wrote parts of the article and were involved in the analysis and reflections on the Policy Labs themselves. JG, RP, BW, AP SHK were all involved in early conceptualisation of Policy Labs. BD and JB contributed to the conceptualisation and analysis for the background scoping of other lab-type activities which influenced some of the early thinking for this article.

\section{Competing interests}

The authors declare no competing interests.

\section{Additional information}

Correspondence and requests for materials should be addressed to S.H.-K.

Reprints and permission information is available at http://www.nature.com/reprints

Publisher's note Springer Nature remains neutral with regard to jurisdictional claims in published maps and institutional affiliations.

\section{(c) (i)}

Open Access This article is licensed under a Creative Commons Attribution 4.0 International License, which permits use, sharing, adaptation, distribution and reproduction in any medium or format, as long as you give appropriate credit to the original author(s) and the source, provide a link to the Creative Commons license, and indicate if changes were made. The images or other third party material in this article are included in the article's Creative Commons license, unless indicated otherwise in a credit line to the material. If material is not included in the article's Creative Commons license and your intended use is not permitted by statutory regulation or exceeds the permitted use, you will need to obtain permission directly from the copyright holder. To view a copy of this license, visit http://creativecommons.org/ licenses/by/4.0/.

(C) The Author(s) 2020 